\title{
História da educação, humanidades digitais e divulgação científica: a biblioteca digital de História da Educação
}

\author{
Ester Fraga Vilas-Bôas Carvalho do Nascimento ${ }^{I}$ \\ Josué dos Santos Alves ${ }^{I I}$
}

\begin{abstract}
Resumo: Na perspectiva da História Cultural, este texto insere-se na História da Educação e na História do Livro e sua relação com as tecnologias digitais. O referencial teóricometodológico ancora-se em Ginzburg (2007), com o método indiciário, em Nascimento (2007), para tratar de instituições protestantes e, em Faria Filho (2000), por tratar da relação da História da Educação com as novas tecnologias. O presente texto discorre acerca da criação da Biblioteca Digital de História da Educação, disponibilizando impressos que circularam no Brasil oitocentista, a difusão de títulos, os temas abordados, editoras e ano de publicação, bem como a importância da ação de protestantes na produção, circulação e usos de impressos e, consequente circulação de ideias, e sua relação com a educação brasileira.
\end{abstract}

Palavras-chave: Biblioteca Digital de História da Educação, humanidades digitais, divulgação científica, impressos, tecnologias digitais.

\section{History of education, digital humanities and cientific divulgation: the digital library of History Education}

\begin{abstract}
In the perspective of Cultural History, this text is inserted in the History of Education and in the History of the Book and its relation with the digital technologies. The theoretical-methodological framework is anchored in Ginzburg (2007), with the indiciario method, in Nascimento (2007), to deal with Protestant institutions and, in Faria Filho (2000), for dealing with the relation of the History of Education with the new technologies. The present text discusses the creation of Digital Library of Educacion History, making available the booklets that circulated in nineteenth-century Brazil, the diffusion of titles, the topics covered, publishers and year of publication, as well as the importance of Protestant action in production, circulation and use of booklets, and consequent circulation of ideas, and its relation with Brazilian education.
\end{abstract}

Keywords: Digital Library of History of Education, digital humanities, cientific divulgation, prints, digital technologies.

Artigo recebido em 10/05/2019 e aprovado em 02/07/2019. 


\title{
HISTÓRIA DA EDUCAÇÃO, HUMANIDADES DIGITAIS E DIVULGAÇÃO CIENTÍFICA: A BIBLIOTECA DIGITAL DE HISTÓRIA DA EDUCAÇÃO
}

\section{ESTER FRAGA VILAS-BÔAS CARVALHO DO NASCIMENTO E JOSUÉ DOS SANTOS ALVES}

O financiamento do $\mathrm{CNPq}$ tem viabilizado a execução do projeto liderado pesquisadora Ester Nascimento, que trata da circulação de impressos protestantes durante o século XIX. E, no ano de 2017, possibilitou a criação de uma base de dados digital, ferramenta de difusão científica, que tem permitido disponibilizar paulatinamente documentos coletados por ela durante os últimos 20 anos. São diversos tipos de fontes a exemplo de cartas, livros, livretos, opúsculos, jornais, fotografias e livros de ata, coletados em diversos acervos, a exemplo do Centro de Documentação e História Vicente Themudo Lessa (São Paulo/SP); do Arquivo Histórico Presbiteriano (São Paulo/SP); da Britsh and Foreign Bible Society's Library/ BFBS Archives Indexes/BSAX (Cambridge University Library, Cambridge/UK) ${ }^{\mathrm{III}}$.

A base de dados intitulada Biblioteca Digital de História da Educação insere-se na História da Educação e sua relação com as Humanidades Digitais. É constituída por documentos da História da Educação que circularam entre o Brasil, a Inglaterra e Portugal, principalmente durante a segunda metade do século XIX, os quais colaboraram na difusão de práticas e saberes educacionais durante os Oitocentos e na possibilidade de se construir novos leitores, num país no qual os dados de pesquisas apontavam para porcentagem significativa de analfabetos. A análise desses impressos e de outros tipos de documentos se caracteriza em um verdadeiro arsenal de fontes para o desenvolvimento da pesquisa na História da Educação.

A disponibilidade de um corpus documental de difícil acesso em formato digital possibilita promover novas possibilidades de investigação de temas que ainda se encontram obscuros na História da Educação brasileira. A Biblioteca Digital de História da Educação tem sido alimentada por impressos protestantes e outros impressos pedagógicos que circularam no Brasil, Inglaterra, e Portugal, entre outros países, durante o século XIX e meados do século XX.

$\mathrm{Na}$ perspectiva da História Cultural, este artigo apresenta resultados parciais quanto ao processo de criação e alimentação dessa base de dados digital, como também, da circulação de impressos, temas abordados, editoras e ano de publicação, bem como a importância da ação de protestantes na produção, difusão e usos dessas fontes, produtos culturais produzidos e disseminados por grupos protestantes e outros. Para Chartier, "a história cultural, tal como a entendemos, tem por principal objetivo identificar o modo como em diferentes lugares e momentos uma determinada realidade social é construída, pensada, dada a ler" ${ }^{\text {,V }}$. Com base nesse princípio, e relacionando com o campo da educação, Chartier, afirma

que:

\begin{abstract}
Em sua definição social e serial, a história do livro visava caracterizar as com imaginações culturais a partir de categorias de textos supostamente específicas. Tal operação revelou-se duplamente redutora. Por um lado, ela assemelha a identificação de diferenças às desigualdades de repartição; por outro, ela ignora os processos através dos quais um texto faz sentido para aqueles que o lêem ${ }^{\mathrm{V}}$.
\end{abstract}

Os livros desencadearam a curiosidade por parte do leitor na Modernidade. Em síntese quando o autor fala sobre a leitura considera que ela,

não é somente uma operação abstrata de intelecção; ela é engajamento do corpo, inscrição num espaço, relação consigo e com os outros. (...) Uma história da leitura não deve, pois, limitar-se à genealogia única da nossa maneira contemporânea de ler em silêncio e com os olhos. Ela tem também e, sobretudo, a tarefa de encontrar os gestos osquecidos, os hábitos desaparecidos ${ }^{\mathrm{VI}}$. 


\title{
HISTÓRIA DA EDUCAÇÃO, HUMANIDADES DIGITAIS E DIVULGAÇÃO CIENTÍFICA: A BIBLIOTECA DIGITAL DE HISTÓRIA DA EDUCAÇÃO
}

ESTER FRAGA VILAS-BÔAS CARVALHO DO NASCIMENTO E JOSUÉ DOS SANTOS ALVES

Considerando o leitor, Chartier destaca que,

\begin{abstract}
A história das práticas da leitura, a partir do século XVIII, é também uma história da liberdade na leitura. É no século XVIII que as imagens representam o leitor na natureza, o leitor que lê andando, que lê na cama, enquanto ao menos na iconografia conhecida, os leitores anteriores ao século XVIII liam no interior de um gabinete, de um espaço retirado e privado, sentados e imóveis ${ }^{\mathrm{VII}}$.
\end{abstract}

Portanto, a fonte que "é a necessária e indispensável matéria-prima do historiador, para que ele possa reconstruir o passado"VIII, ajuda o pesquisador na execução de suas investigações. Entre as novas fontes que têm se tornado fundamental nos estudos usados para elucidar as pesquisas de História da Educação estão as cadernetas de professores, utensílios, provas, exercícios, boletins escolares, cadernos e trabalhos de alunos, livros etc.

Uma dessas fontes foram impressos que circularam no Brasil, Jorge Nascimento, em seu texto intitulado "Nota prévia sobre a palavra impressa no Brasil do século XIX: a Biblioteca do Povo e das Escolas", ressalta que os primeiros livros escolares adotados entre nós foram trazidos pelos jesuítas. Ressalta também que com a chagada dos padres jesuítas em território brasileiro começaram a ser formadas as primeiras bibliotecas.

Segundo Jorge Nascimento, no século XIX, o Brasil começou a produzir os seus próprios livros didáticos, através da Impressão Régia. Isto ocorreu em função das guerras napoleônicas e da interrupção do envio de livros produzidos na Europa para cá. Um dos traços caracterizadores dos séculos XIX e XX, foi a problemática acerca da educação que se fazia presente, problemas que envolviam o mercado de produção e circulação de livros naquele momento no Brasil $^{\mathrm{IX}}$.

No entanto, já existia literatura trabalhada de acordo com os problemas enfrentados na época, onde se fazia uso de impressos que circulavam para que o povo tivesse acesso à leitura. No final do século XIX, a Biblioteca do Povo e das Escolas alcança no Brasil um enorme sucesso editorial, visto que, o planejado era apenas a produção de oito séries. Porém, foram publicadas mais de 21 séries em 42 anos, com recordes de venda exemplares. Este é um dos exemplos que mostra o interesse do brasileiro pela leitura, e através dela o desenvolvimento do senso crítico e sociopolítico ainda no século XIX. O autor ainda destaca que,

\begin{abstract}
A Biblioteca do Povo e das Escolas é uma grata surpresa, quando se observa atentamente e se percebe que em um país no qual a maioria dos livros não alcançava a casa dos 300 exemplares vendidos anualmente, tal coleção tenha vendido, nos seus dois primeiros volumes, 6000 exemplares a cada 15 dias, em Portugal e no Brasil, já que mesmo livros de boa vendagem raramente superavam seiscentos ou oitocentos exemplares por ano ${ }^{\mathrm{x}}$.
\end{abstract}

Ester Nascimento, em seu texto "Associações voluntárias, missões protestantes e a História da Educação", traz com detalhes, uma análise teórica sobre a ação de protestantes britânicos, vinculados à Sociedade Bíblica Britânica e Estrangeira/BFBS e, de missionários presbiterianos norte-americanos no Brasil, durante o século $\mathrm{XIX} \mathrm{XI}^{\mathrm{XI}}$. As sociedades bíblicas eram associações voluntárias, funcionando desde o início do século XIX como instrumentos de intervenção internacional na área religiosa. Eram organizações administrativas pertencentes a comunidades protestantes com o objetivo de manter a propaganda evangélica no seu país e no estrangeiro. 


\section{HISTÓRIA DA EDUCAÇÃO, HUMANIDADES DIGITAIS E DIVULGAÇÃO CIENTÍFICA: A BIBLIOTECA DIGITAL DE HISTÓRIA DA EDUCAÇÃO}

\section{ESTER FRAGA VILAS-BÔAS CARVALHO DO NASCIMENTO E JOSUÉ DOS SANTOS ALVES}

O surgimento das sociedades bíblicas ocorreu paralelamente ao florescimento de outras sociedades voluntárias, como as igrejas e as missões, com propósitos tanto religiosos quanto civis, mantendo o vigor das atividades cristãs. No final do século XIX, elas já tinham organizado um sistema de distribuição de impressos em mais de 70 países.

As sociedades voluntárias, ou sociedade de ideias, - maçônicas, patrióticas, literárias, religiosas etc - foram formas modernas de sociabilidade que ofereceram "novos modelos associativos em meio de uma sociedade globalmente organizada em torno de uma estrutura corporativa hierárquica (ordens) e composta na essência por atores sociais coletivos". Como contraponto da sociedade tradicional, do Antigo Regime, aquelas organizações foram "portadoras da modernidade, no sentido de que estruturavam novas formas de organização do social, não centradas sobre os antigos grupos, mas no indivíduo como ator político e social". Eram caracterizadas pelo fato de "cada um de seus membros terem somente uma relação com as ideias, com os fins". Aquelas novas associações funcionaram como laboratórios democráticos nos quais seus membros se educavam pela prática política moderna enquanto indivíduo-cidadão que exercia sua soberania como parte do grupo de eleitores ${ }^{\mathrm{XII}}$.

A estratégia de distribuir impressos antecedeu à organização de igrejas e escolas organizadas por missões protestantes norte-americanas, com a finalidade de implantar definitivamente o Protestantismo no Brasil. Como essa estratégia teve sucesso num país que, na época, possuía uma população analfabeta em sua maioria? O que poderia ser visto como um problema era, na verdade, o diferencial. Quando o vendedor ambulante chegava num determinado local que as pessoas não sabiam ler, ele propunha a organização de um grupo e se comprometia em enviar um professor para ensiná-los, que, na verdade também era um missionário. Dessa maneira, eles mapearam no Brasil o território de instalação de suas futuras igrejas e escolas. Os resultados iniciais demonstram que a intervenção de instituições protestantes na circulação e difusão de impressos possibilitou a definitiva inserção do Protestantismo no país.

A distribuição de impressos protestantes por agentes e vendedores ambulantes, vinculados à Sociedade Bíblica Britânica e Estrangeira/BFBS e à Sociedade Bíblica Americana/ABS, se tornou um dos meios mais eficazes da propagação do Protestantismo no Brasil do século XIX ${ }^{\mathrm{XIII}}$. Outro fator importante na implantação do Protestantismo no Brasil foi o trabalho dos vendedores ambulantes de impressos protestantes. Muitos desses homens foram responsáveis pela implantação de vários grupos de protestantes, travando embates com lideranças católicas dos locais que passavam. A religião protestante teve como aliada a educação, uma vez que, os missionários alfabetizavam através dos impressos protestantes, estes usados tanto como material didático nas escolas protestantes quanto material religioso, contribuindo, assim, para o progresso da leitura, da educação e da sociedade brasileira.

Durante a década de 40 do século XIX, seis agentes da BFBS atuaram nas Províncias do Rio de Janeiro, Bahia, Alagoas e Pará: Edward Parker, William Dadson, James Henderson, James Burnett, James Hogg e J. F. Lippold. Na década seguinte, Edward Parker, William Dadson e James Hogg, continuavam atuando porém, juntaram-se a eles os agentes James Flecher, Henry Hadley e Nathaniel Sands atuantes no Rio de Janeiro, além de William Elliot e Verqueiro na Província de São Paulo. Na década de 60, Alexander Latimer Blackford foi o único encontrado em atuação, localizado na Província do Rio de Janeiro. Nos anos 70 Alexander Latimer ainda atuava, acompanhado a partir de então por G. Caley, José M. Martins de Carvalho, Robert Reid Kalley e Edward Lane, ampliando a atuação para as Províncias da Bahia e São Paulo. Na última década que registra a atuação da BFBS no Brasil, encontramos o agente J. M. J. dos Santos atuando no Rio de Janeiro. 


\section{HISTÓRIA DA EDUCAÇÃO, HUMANIDADES DIGITAIS E DIVULGAÇÃO CIENTÍFICA: A BIBLIOTECA DIGITAL DE HISTÓRIA DA EDUCAÇÃO}

\section{ESTER FRAGA VILAS-BÔAS CARVALHO DO NASCIMENTO E JOSUÉ DOS SANTOS ALVES}

Quando os agentes britânicos e norte-americanos chegaram ao Brasil com a tarefa específica de divulgar o Protestantismo, encontraram um país que possuía grupos favoráveis à sua implantação, como foi o caso dos maçons e republicanos, mesmo considerando as constantes perseguições da Igreja Católica, que viam o Protestantismo como uma ameaça. Esse movimento ocorreu a partir da primeira metade do século XIX, quando eles se estabeleceram no Rio de Janeiro, Maranhão, Bahia, Rio Grande do Sul, Santa Catarina, Pernambuco, Paraíba, Alagoas, entre outros.

O analfabetismo era um obstáculo para conversão baseada na leitura da Bíblia, dificultando inclusive o progresso e ascensão social, ideia firmemente plantada pela corrente liberal. Portanto, a principal aspiração dos membros das Sociedades Bíblicas e dos missionários era efetivar a leitura da Bíblia para que, dessa maneira, pudessem ser evangelizados. A força que os missionários encontravam para encarar esse objetivo de evangelizar um país, vinha da crença de que eram iluminados por Deus e que tinha o dom de espalhar sua palavra a todos aqueles que necessitavam. Ou seja, para eles, civilizar significava oferecer àquela sociedade a salvação do espírito e do corpo, através dos seus preceitos religiosos.

A execução deste projeto tem permitido investigar a difusão de saberes e práticas educacionais e religiosas no Brasil, principalmente durante a segunda metade dos Oitocentos, período de publicação e circulação dos impressos que compõem a Coleção Folhetos Evangélicos, de Vicente Themudo Lessa. Este homem foi um leitor, escritor, historiador, pastor, ou seja, um intelectual brasileiro que viveu no século XIX e durante as primeiras décadas do século XX. Possuía uma biblioteca particular composta por mais de 5.000 obras, além desta coleção, organizada com 644 títulos, encadernados em 47 volumes, que circularam no Brasil a partir de meados dos Oitocentos, sobre diversos temas, como demonstra o quadro a seguir.

\begin{tabular}{|} 
QUADRO 1: TEMAS DA COLEÇÃO FOLHETOS EVANGÉLICOS \\
\begin{tabular}{|c|c|}
\hline TEMA & QUANTIDADE \\
\hline Protestantismo & 389 \\
\hline Educação & 106 \\
\hline Catolicismo X Protestantismo & 55 \\
\hline Catolicismo & 41 \\
\hline Espiritismo & 31 \\
\hline Maçonaria & 22 \\
\hline
\end{tabular}
\end{tabular}

Fonte: Coleção Folhetos Evangélicos. São Paulo: Centro de Documentação e História

Reverendo Vicente Themudo Lessa, 2010.

Segundo Almeida, os centros editoriais responsáveis pelas produções dos impressos que compõem a Coleção Folhetos Evangélicos eram comerciais, protestantes e católicas e, estavam localizadas principalmente, nos Estados Unidos, Portugal e Brasil. Os 414 títulos publicados no Brasil, foram produzidos por 48 tipografias localizadas em São Paulo (17), Rio de Janeiro (15), Paraná (02), Bahia (02), Maranhão (01), Curitiba (01), Rio Grande do Sul (01), Porto Alegre (01), Jaú (01), Caxias (01), Juiz de Fora (01), Garanhuns (01), Paraíba (01), Belém (01), Fortaleza (01), Natal (01). Dos 79 títulos publicados em Portugal, 10 foram produzidos em tipografias localizadas em Lisboa e, nove, em Porto. Já os Estados Unidos, foram responsáveis pela produção de 45 títulos produzidos em Nova Iorque, Califórnia e, Filadélfia. Na Inglaterra, foram impressos cinco e, França e Escócia, cada um com um título. 


\section{HISTÓRIA DA EDUCAÇÃO, HUMANIDADES DIGITAIS E DIVULGAÇÃO CIENTÍFICA: A BIBLIOTECA DIGITAL DE HISTÓRIA DA EDUCAÇÃO}

\section{ESTER FRAGA VILAS-BÔAS CARVALHO DO NASCIMENTO E JOSUÉ DOS SANTOS ALVES}

Não foi possível, registrar a localização da produção de 99 títulos pela ausência de elementos editoriais ${ }^{\mathrm{XIV}}$.

Dentre os centros editoriais portugueses, a Livraria Evangélica, localizada em Lisboa. Criada em Portugal, em 1864, era uma Agência da Sociedade de Tratados Religiosos que contribuía, "anualmente com uma determinada quantia que permitia a manutenção regular do trabalho da Livraria em Portugal, nas Colônias e no Brasil". No ano de 1913, "se separou da Sociedade Bíblica Britânica e Estrangeira. Apesar de continuarem a cooperar, à Sociedade Bíblica coube continuar a difusão de Bíblias, Testamentos e Porções [...]”, pela intensificação da ação de colportagem, enquanto que "a Livraria incidiu na atividade editorial. Com a redefinição operada, cada uma das instituições seguiu caminhos diferentes". Em 1935, a Livraria Evangélica encerrou suas atividades, calculando que até aquele momento, ela conseguira produzir anualmente uma quantidade "superior a 2.000 exemplares de Livros e Tratados"XV.

Dentre as publicações produzidas em Portugal, encontram-se estatutos e relatórios. Segundo Afonso, "o rigor em publicitar os prelos e em apresentar as contas, demonstra o zelo ao cumprimento rigoroso do legado e também se procura rentabilizar o legado". O referido autor afirma que a produção de documentos para a evangelização, "enquanto projeto editorial, foi central, mas, tendo sempre presente que tais documentos fossem uma marca identitária para os cristãos reformados [...] daí a grande aposta na difusão gratuita através do correio"XVI .

Muitos estudos foram publicados como resultado destas investigações, possibilitando um vigoroso debate de revisão quanto a interpretações acerca da História da Educação no Brasil, carregadas de preconceitos próprios da historiografia educacional dos primeiros 80 anos do século XX, a exemplo da certeza que se estabeleceu segundo a qual a leitura entre nós durante o século XIX teria sido inacessível não apenas ao povo, mas a toda a sociedade brasileira.

Como resultado das investigações até agora realizadas foi possível constatar fatos como a expansão do mercado editorial brasileiro no século XIX e o incremento que lhe foi oferecido por iniciativas como o funcionamento regular dos correios, a partir de 1830 . Também é válido anotar providências como a regulamentação, em 1866, da propriedade sobre a obra literária pelos herdeiros do autor por 50 anos após sua morte, tornando-se em seguida de domínio público. Um bom exemplo do aquecimento do mercado editorial pode ser verificado com a entrada em circulação da Biblioteca do Povo e das Escolas, uma coleção de 237 livros, publicados durante 42 anos, entre 1881 e 1913, pela Editora David Corazzi, de Lisboa, que circulou em Portugal e no Brasil. Os volumes eram publicados quinzenalmente, nos dias 10 e 25 de cada mês, cada um com rigorosas 64 páginas, em formato de $15,5 \times 10$ centímetros, de composição cheia ${ }^{\mathrm{XVII}}$. A edição dos dois primeiros volumes foi de 6 mil exemplares cada. A partir do terceiro volume começaram a ser impressos 12 mil exemplares de cada vez. A tiragem subiu para 15 mil exemplares a partir do volume $10^{\mathrm{XVIII}}$.

De acordo com Domingos Ribeiro, um dos historiadores do Protestantismo no Brasil, no período de 100 anos, entre 1835 e 1935, teriam circulado no país cerca de um milhão de exemplares de impressos protestantes ${ }^{\mathrm{XIX}}$. No entanto, as investigações realizadas por esta pesquisadora no acervo da Cambridge University Library demonstraram que a Sociedade Bíblica Britânica e Estrangeira estava no Brasil desde o ano de 1818, e não, a partir do ano de 1835, possibilitando inferir que esse quantitativo de impressos deve ter sido bem maior.

É recorrente encontrar em documentos do século XIX, queixas como as formuladas em 1829, pelo missionário norte-americano Daniel Parish Kidder quanto a ausência de livros didáticos produzidos em território brasileiro ou, ao menos, adequados às condições locais. Tal problema era visto como impeditivo ao desenvolvimento da educação nacional. Mesmo o 


\section{HISTÓRIA DA EDUCAÇÃO, HUMANIDADES DIGITAIS E DIVULGAÇÃO CIENTÍFICA: A BIBLIOTECA DIGITAL DE HISTÓRIA DA EDUCAÇÃO}

\section{ESTER FRAGA VILAS-BÔAS CARVALHO DO NASCIMENTO E JOSUÉ DOS SANTOS ALVES}

esforço de editores como Baptiste Garnier não seria suficiente para o suprimento das necessidades brasileiras na área. As dificuldades do mercado brasileiro do livro didático teriam possibilitado que durante toda a segunda metade do século XIX e pelo menos durante as duas primeiras décadas do século XX muitos editores portugueses continuassem a produzir livros escolares - didáticos e complementares do trabalho escolar - destinados a estudantes portugueses e brasileiros.

Todavia, quando analisamos detalhadamente algumas questões, observamos que Kidder e seu parceiro de publicações na metade do século XIX, James Cooley Fletcher, desenvolveram um intenso trabalho objetivando a circulação de impressos e as práticas de leitura entre nós. Ambos atuaram no Brasil como missionários e representaram algumas associações norte-americanas. Kidder era metodista e viajou pelo Brasil vendendo Bíblias como representante da Sociedade Bíblica Americana/ABS. Ainda em 1829, segundo Reily, ele propôs à Assembleia Legislativa da Imperial Província de São Paulo o fornecimento gratuito de exemplares do Novo Testamento, traduzido para a língua portuguesa pelo Padre Antônio Pereira de Figueiredo, em quantidade suficiente para entregar 12 exemplares a cada uma das escolas primárias da Província, mediante a condição única de que tais volumes fossem desembaraçados, quando entregues à Alfândega do Rio de Janeiro, distribuídos, conservados e usados pelas diversas escolas, como livros de leitura geral e instrução para seus alunos $\mathrm{XX}$.

Além do seu trabalho como missionário, Fletcher foi também secretário interino da Legação dos Estados Unidos no Rio de Janeiro. Esforçou-se muito por estimular também o comércio e o intercâmbio entre os dois países, Brasil e Estados Unidos. Seguro de que o progresso resultaria um maior relacionamento dos brasileiros com a América do Norte, Fletcher considerava tal atividade como parte integrante da sua missão e os resultados como legítimo fruto missionário. A partir de 1851, ele passou a trabalhar no Brasil como Agente da União Cristã Americana e Estrangeira, da Sociedade Americana dos Amigos dos Marinheiros e da Sociedade Bíblica Americana em uma missão que durou até 1854, distribuindo impressos por todo o país ${ }^{X X}$. Durante a sua atuação, entre 1855 e 1856, como Agente da União Americana de Escolas Dominicais, Fletcher viajou quase cinco mil quilômetros no interior do país distribuindo Bíblias, um dos objetivos daquela organização. Durante os anos de 1868 e 1869, voltou a atuar como Agente da Sociedade Americana de Panfletos.

\section{A biblioteca digital de história da educação}

Segundo Gondra, a utilização de novos recursos para suporte à pesquisa histórica, é uma imposição da atualidade aos investigadores da área da História da Educação, "não devendo se limitar à aplicação técnica, mas se estender ao exame de processos tecnológicos que venham a potencializar a exploração de fontes"XXII. Para Alves e Nascimento,

as tecnologias digitais e a globalização dos textos eletrônicos, possibilita ao leitor buscar várias interpretações, de vários autores, de qualquer século passado em qualquer lugar do planeta, não importando a distância, estando ele apenas conectado à rede eletrônica mundial de computadores ${ }^{\mathrm{XXIII}}$. 


\section{HISTÓRIA DA EDUCAÇÃO, HUMANIDADES DIGITAIS E DIVULGAÇÃO CIENTÍFICA: A BIBLIOTECA DIGITAL DE HISTÓRIA DA EDUCAÇÃO}

\section{ESTER FRAGA VILAS-BÔAS CARVALHO DO NASCIMENTO E JOSUÉ DOS SANTOS ALVES}

A relação entre texto e imagem na tela, tende a aperfeiçoar, pois já eram perceptíveis nos livros impressos, a assimilação e curiosidade do leitor pela obra. Tratando do leitor e as novas tecnologias, Chartier compreende que,

o leitor da tela assemelha-se ao leitor da antiguidade: o texto que ele lê corre diante de seus olhos; é claro, ele não flui tal como o texto de um livro em rolo, que era preciso desdobrar horizontalmente, já que agora ele corre verticalmente. De um lado, ele é como o leitor medieval ou o leitor do livro impresso, que pode utilizar referencias como a paginação, o índice, o recorte do texto. Ele é simultaneamente esse dois leitores. Ao mesmo tempo é mais livre ${ }^{\mathrm{XXIV}}$.

Chartier entende que,

O texto eletrônico poderia, supor a retomada da leitura no espaço doméstico e privado ou nos lugares em que a utilização dos bancos de dados informáticos, das redes eletrônicas, é a mais importante. (...) A trajetória desse novo meio poderia levar a uma forma de leitura mais privada do que aquela que a precedia, por exemplo, na biblioteca. ${ }^{\mathrm{XXV}}$

O uso das novas teccnologias digitais para a investigação/análise tanto nas pesquisas educacionais, como nas pesquisas na rede mundial de internet por meio dos suports eletrônicos, também possibilita o armazenamento de materiais. A utilização de tenologias digitais "para o trato documental pode subsidiar pesquisas históricas no tocante à conservação dos dados, consulta integrada e exploração de novos conhecimentos em base de dado". XXVI

A Biblioteca Digital de História da Educação foi criada junto ao Google Site que integra a plataforma de ferramentas Google for Education e está sendo alimentada por integrantes do Grupo de Pesquisa História das Práticas Educacionais/GPHPE/Unit/CNPq alunos de Iniciação Científica, de Mestrado e de Doutorado -. Até o momento, foram inseridos o equivalente a 1.448 fotogramas referentes a 19 impressos da Coleção Folhetos Evangélicos - livros, livretos e folhetos -,os quais vêm acompanhados de resumo, refência bibliográfica, origem do documento.

O site Biblioteca Digital de História da Educação contém sete páginas distintas, são elas: Página Inicial, Folhetos, Jornais, Livros, Livretos, Opúsculos, Revistas. Será possível realizar pesquisas no site através do nome do autor, de palavras-chaves, título do livro, ano de publicação. Até o final do ano em curso, o site será disponibilizado para toda rede mundial de pesquisadores, nos idiomas português, inglês, espanhol e poderá ser acessado por vários aparelhos eletrônicos, como por exemplo: smartphones, computadores, tablets etc. Apesar de ser programado para todo público, os professores poderão usá-lo durante as suas aulas em qualquer ambiente que esteja.

A G Suite for Education, existe há 10 anos. Inicialmente foi denominada de Google Apps for Education, e sua criação e desenvolvimento tem como principal objetivo compartilhar formas inovadoras de práticas de aprendizagem entre professores e alunos desde o nível fundamental até o nível superior. A tecnologia do Google for Education possibilita aos educadores manter o aprendizado personalizado, garantindo melhor desempenho de suas turmas. Já os alunos se beneficiam com a facilidade da plataforma e ganham mais tempo para aprendizagem $^{\text {XXVII }}$.

Esta atividade também tem possibilitado trabalhar com um tipo de discente que possui acesso a informação que disponibilizamos em sala de aula praticamente em tempo real. Logo, apresentar a este novo tipo de aluno novas propostas de aprendizagem, conectadas ao seu universo, é fundamental no processo de ensino aprendizagem. Concordamos quando 


\section{HISTÓRIA DA EDUCAÇÃO, HUMANIDADES DIGITAIS E DIVULGAÇÃO CIENTÍFICA: A BIBLIOTECA DIGITAL DE HISTÓRIA DA EDUCAÇÃO}

\section{ESTER FRAGA VILAS-BÔAS CARVALHO DO NASCIMENTO E JOSUÉ DOS SANTOS ALVES}

Assmann afirma que "o produto dessa nova educação deve caracterizar-se por experiências de aprendizagem e não pela aquisição de conhecimentos supostamente prontos e disponíveis para o ensino concebido como simples transmissão"XXVIII.

Portanto, "o leitor da era digital adquire novas formas de ler, diferente da leitura de um livro impresso, seja em um espaço físico mais reservado, fazendo com que ele esteja isolado numa leitura singular", independente do lugar que ele esteja, podendo ser "[...] em um ambiente aberto ao público, como no ônibus, no metrô, no shopping, em uma praça". Nesse caso, "[...] o leitor da era digital que estará sempre voltado à sua tela" com isso ele "[...] desenvolve novas habilidades e técnicas, ganhando suas características e peculiaridades, construindo a cultura do leitor de textos eletrônicos"XXIX .

O suporte eletrônico proporciona ao leitor uma universalidade de livros, abrindo-se um leque de possibilidades na pesquisa, fazendo suas buscas eletronicamente tornarem-se um trabalho simplificado, que é uma vantagem para o pesquisador.

As humanidades digitais é uma ciência que veio para complementar os olhos dos pesquisadores. E vem se mostrando muito trabalhada pela comunidade da ciência e informação pela perspectiva de produzir uma plataforma, um espaço de compartilhamento de dados abertos para a pesquisa, trazendo programas que auxiliam na observação mais distante, englobando os diversos detalhes existentes que o pesquisador muitas vezes passa despercebido.

As humanidades digitais designam uma transdisciplina, portadora dos métodos, dos dispositivos e das perspetivas heurísticas ligadas ao digital no domínio das Ciências Humanas e Sociais. Mobilizam simultaneamente os instrumentos e as perspectivas singulares do mundo digital. Procuram atuar na intricada relação entre práticas tradicionais e novas tecnologias, construindo ferramentas que auxiliem na criação e na manipulação de novas formas de representações. Além disso, incorporam saberes tradicionais às tecnologias computacionais, aplicando, assim, a tecnologia digital nas investigações em história $^{\mathrm{XXX}}$.

A opção da sociedade pela era digital na atualidade tem alterado o mundo, não sendo diferente com a produção e divulgação do conhecimento. As humanidades digitais designam uma transdisciplina, portadora dos métodos, dos dispositivos e das perspetivas heurísticas ligadas ao digital no domínio das Ciências Humanas e Sociais. Mobilizam simultaneamente os instrumentos e as perspectivas singulares do mundo digital. Procuram atuar na intricada relação entre práticas tradicionais e novas tecnologias, construindo ferramentas que auxiliem na criação e na manipulação de novas formas de representações. Além disso, incorporam saberes tradicionais às tecnologias computacionais, aplicando, assim, a tecnologia digital nas investigações em história ${ }^{\mathrm{XXI}}$.

A criação da Biblioteca Digital de História da Educação também tem o objetivo de proporcionar uma melhor divulgação científica de um corpus documental de difícil acesso e pouco conhecido pelos pesquisadores brasileiros de História da Educação. Segundo Porto e Morais,

no que diz respeito à divulgação científica, dentre todas as tecnologias comunicacionais, é a Internet que tem provocado transformações mais significativas no processo de produção da informação. Isto quer dizer que nenhum outro meio tem possibilitado, com a mesma intensidade, o desenvolvimento de modelos de comunicação democráticos, onde o público participa do debate sobre a ciência e seu papel social, com suas opiniões, valores, expectativas ou preocupações. Diante disso, e com base em tudo o que foi exposto até aqui, é viável afirmar que as 


\title{
HISTÓRIA DA EDUCAÇÃO, HUMANIDADES DIGITAIS E DIVULGAÇÃo CIENTÍFICA: A BIBLIOTECA DIGITAL DE HISTÓRIA DA EDUCAÇÃO
}

ESTER FRAGA VILAS-BÔAS CARVALHO DO NASCIMENTO E JOSUÉ DOS SANTOS ALVES

\begin{abstract}
políticas de incentivo à popularização da ciência, que se multiplicaram sensivelmente nos últimos anos, em função de parcerias entre órgãos governamentais, a iniciativa privada e a sociedade, devem contemplar as potencialidades da Internet. Dentre essas potencialidades, a mais significativa é a possibilidade de acesso fácil e gratuito, que pode contribuir, de forma decisiva, para a formação de uma cultura científica no Brasil ${ }^{\mathrm{XXII}}$.
\end{abstract}

As tecnologias estão cada vez mais importante e surpreendente nas atividades humanas e na concepção digital. Todos os tipos de acervo são convergidos em conteúdo digital ou pela facilidade em ter acesso a esse conteúdo, as informações e aos dados. Assim as humanidades vieram para possibilitar e a auxiliar na comunicação intercontinental em rede, como por aumentar excelentemente a total capacidade de armazenamento e processamento de dados. Essa área de pesquisa tem se fortalecido no âmbito acadêmico com o passar do ultimos anos.

Em função do rápido desenvolvimento das mídias digitais as Humanidades se transformaram bastante. Atualmente, são utilizados: pesquisa em acervos digitalizados; consulta em bancos de teses online; artigos acadêmicos em revistas digitais baixados ensinar pela plataforma eletrônica; produzir mapas, criar complexos bancos de dados e organizar nossas referências bibliográficas com a ajuda de softwares.

\section{CONSIDERAÇÕES FINAIS}

As tecnologias digitais ${ }^{\mathrm{XXIII}}$ e a globalização dos textos eletrônicos, têm possibilitado ao leitor do século XXI, buscar várias interpretações, de vários autores, de qualquer século, em qualquer lugar do planeta, não importando a distância, estando ele apenas conectado a rede eletrônica mundial de computadores.

O leitor da era digital adquire novas formas de ler e, consequentemente, novas maneiras de apreender o conteúdo, diferente da leitura de um livro impresso, seja em um espaço físico mais reservado, fazendo com que ele esteja isolado numa leitura singular, ou em um ambiente aberto ao público, como no ônibus, no metrô, no shopping, em uma praça. Nesse caso, o leitor da era digital está voltado simplesmente à sua tela. Com isso, ele desenvolve novas habilidades e técnicas, ganhando suas características e peculiaridades, construindo a cultura do leitor de textos eletrônicos.

Portanto, o projeto que tem sido desenvolvido demonstra a importância da circulação de impressos e sua relação com a Educação. Ainda que num futuro não distante, já não exista mais impressos ou manuscritos, toda a documentação coletada pela Coordenadora desta pesquisa estará disponível na internet, por meio de tecnologias digitais, disponibilizando aos pesquisadores de todo mundo, impressos que circularam no Brasil oitocentista e auxiliaram na difusão de novas ideias na sociedade.

Não somente os historiadores do livro e da leitura, ou aqueles que investigam e trabalham com tecnologias digitais, mas pesquisadores da área da Educação, poderão compreender melhor o impacto da palavra impressa e da palavra digital em distintos grupos sociais.

\section{Notas}

Cadernos do Tempo Presente, São Cristóvão-SE, v. 10, n. 01, p. 12-24, jan./jul. 2019|

http://www.seer.ufs.br/index.php/tempo 


\title{
HISTÓRIA DA EDUCAÇÃO, HUMANIDADES DIGITAIS E DIVULGAÇÃO CIENTÍFICA: A BIBLIOTECA DIGITAL DE HISTÓRIA DA EDUCAÇÃO
}

\author{
ESTER FRAGA VILAS-BÔAS CARVALHO DO NASCIMENTO E JOSUÉ DOS SANTOS ALVES
}

\begin{abstract}
${ }^{\text {I }}$ Pós-Doutora pela Universidade de Aveiro. Doutora em Educação pela Pontifíicia Universidade Católica de São Paulo (PUC/SP). Bolsista de Produtividade em Educação pelo CNPq, desde 2012. Professora do Programa de Pós-Graduação em Educação da Universidade Tiradentes (UNIT). Coordena o Grupo de Pesquisa História das Práticas Educacionais/PPED/UNIT/CNPq. Esse trabalho tem o apoio financeiro do Edital Universal 01/2016/Faixa B/CNPq. E-mail: esterfraga@gmail.com.

${ }^{\text {II }}$ Mestrando em Educação pelo Programa de Pós-Graduação em Educação da Universidade Tiradentes. Bolsista CAPES/PROSUP. Membro do Grupo de Pesquisa História das Práticas Educacionais/PPED/UNIT/CNPq. E-
\end{abstract} mail: josu.edf@outlook.com.

III BRITISH AND FOREIGN BIBLE SOCIETY'S LIBRARY. Archives Indexes/BSAX (1804-1897). Londres: Cambridge University Library, 1956.

${ }^{\text {IV }}$ CHARTIER, Roger. A História cultural: entre práticas e representações. Tradução Maria Manuela Galhardo. Rio de Janeiro: Bertrand Brasil, 1990, p. 16.

${ }^{\vee}$ CHARTIER, Roger. A ordem dos livros: leitores, autores e bibliotecas na Europa entre os séculos XIV e XVIII. Brasília: Editora Universidade de Brasília, 1998, p. 16.

${ }^{\mathrm{VI}}$ CHARTIER, Roger. A ordem dos livros: leitores, autores e bibliotecas na Europa entre os séculos XIV e XVIII. Brasília: Editora Universidade de Brasília, 1998, p. 16.

VII CHARTIER, Roger. A aventura do livro: do leitor ao navegador. Tradução Reginaldo de Moraes. São Paulo: Editora UNESP/Imprensa oficial do Estado, 1999, p. 78.

VIII LOPES, Eliane M. T. GALVÃO, Ana Maria de O. Território plural: a pesquisa em hitória da educação. São Paulo: Ática, 2010, p. 65.

IX NASCIMENTO, Jorge Carvalho do. Nota prévia sobre a palavra impressa no Brasil do século XIX: a Biblioteca do Povo e das Escolas. Revista Horizontes. Bragança Paulista: USF, 2001, p. 11-28.

${ }^{\mathrm{X}}$ NASCIMENTO, Jorge Carvalho do. Nota prévia sobre a palavra impressa no Brasil do século XIX: a Biblioteca do Povo e das Escolas. Revista Horizontes. Bragança Paulista: USF, 2001, p. 8.

${ }^{\mathrm{XI}}$ NASCIMENTO, Ester Fraga Vilas-Bôas Carvalho do. Brasil, Portugal e Inglaterra: circulação de impressos protestantes no Norte do Brasil. Anais Eletrônicos do III Congresso Nordestino de Ciências da Religião. Recife: UNICAP, 2016, p. 1-13.

XII BASTIAN, Jean-Pierre (Comp.). Protestantes, liberales y francmasones. Sociedades de ideas y modernidad en América Latina, siglo XIX. México: Fondo de Cultura Económica/CEHILA, 1993, p. 8.

XIII AMERICAN BIBLE SOCIETY. The Manual of the American Bible Society. From the One Hundred and Tenth Annual Report of the American Bible Society. New York: American Bible Society Press, 1926.

XIV ALMEIDA, M. S. Livros e leitores: saberes e práticas educacionais e religiosas na Coleção Folhetos Evangélicos (1860-1939). Aracaju: Universidade Tiradenes, 2013. Dissertação de Mestrado, p. 62-69.

$\mathrm{xV}$ AFONSO, José António. Protestantismo e Educação. História de um projecto pedagógico alternativo em Portugal na transição do séc. XIX. Braga: Univ. do Minho/Instituto de Educação e Psicologia, 2009, p. 295-297.

${ }^{\mathrm{XVI}}$ AFONSO, José António. Protestantismo e Educação. História de um projecto pedagógico alternativo em Portugal na transição do séc. XIX. Braga: Univ. do Minho/Instituto de Educação e Psicologia, 2009, p. 287.

XVII Hallewell esclarece que à época o formato corrente do livro em circulação no Brasil era o chamado formato francês, "ao qual a maioria dos livros brasileiros se ajustou durante 60 anos ou mais. Esse formato existia em dois tamanhos: in-oitavo (16,5 X 10,5 centímetros), e outro muito mais freqüente, o longo in-doze (17,5 X 11,0 centímetros)" HALLEWEL, Laurence. O Livro no Brasil. São Paulo, T. A. Queiroz/Editora da Universidade de São Paulo, 1985, p. 146.

XVIII NASCIMENTO, Jorge Carvalho do. Nota prévia sobre a palavra impressa no Brasil do século XIX: a biblioteca do povo e das escolas. Revista Horizontes. Bragança Paulista: USF, 2001, p. 11-28.

XIX RIBEIRO, Domingos. 1937. Origens do evangelismo brasileiro. Rio de Janeiro: Apollo.

XX REILY, Ducan Alexander. História documental do Protestantismo no Brasil. São Paulo: ASTE, 1984.

${ }^{\mathrm{XXI}}$ KIDDER, D. P. E FLETCHER, J. C. O Brasil e os brasileiros (esboço histórico). $7^{\mathrm{a}}$ ed. São Paulo: Companhia Editora Nacional. Vol. 1, 1941, p. 70-75.

XXII GONDRA, José G. A leveza dos bits. In: FARIA FILHO, Luciano Mendes. Arquivos, fontes e novas tecnologias: questões para a História da Educação. Campinas: Editores Associados, 2000, p. 3-17.

XXIII ALVES, Josué dos S.; NASCIMENTO, Ester F. V. C. do. Construção de uma base de dados da História da Educação Protestante. Anais Eletrônicos do III Seminário Debates do Tempo Presente: Desafios para as humanidades em tempos de crise. São Cristóvão: UFS, 2018, p. 1.

XXIV CHARTIER, Roger. A aventura do livro: do leitor ao navegador. Tradução Reginaldo de Moraes. São Paulo: Editora UNESP/Imprensa Oficial do Estado, 1999, p. 13.

XXv CHARTIER, Roger. A aventura do livro: do leitor ao navegador. Tradução Reginaldo de Moraes. São Paulo: Editora UNESP/Imprensa Oficial do Estado, 1999, p. 142. 


\title{
HISTÓRIA DA EDUCAÇÃO, HUMANIDADES DIGITAIS E DIVULGAÇÃO CIENTÍFICA: A BIBLIOTECA DIGITAL DE HISTÓRIA DA EDUCAÇÃO
}

ESTER FRAGA VILAS-BÔAS CARVALHO DO NASCIMENTO E JOSUÉ DOS SANTOS ALVES

\begin{abstract}
XXVI ROCHA, Fábio Gomes. Mineração de dados educacionais (Educational Data Mining - edm): construindo conhecimento acerca da história da educação por meio dos impressos protestantes. Aracaju: Unit, 2017, p. 8.

XXVII GOOGLE FOR EDUCATION. Disponível em $<<$ https://edu.google.com/ >>. Acessado em 3 de abril de 2019.

XXVIII ASSMANN, H. Reencantar a educação: rumo à sociedade aprendente. Petrópolis: Vozes, 1998, p 32.

XXIX ALVES, Josué dos S.; NASCIMENTO, Ester F. V. C. do. Construção de uma base de dados da História da Educação Protestante. Anais Eletrônicos do III Seminário Debates do Tempo Presente: Desafios para as humanidades em tempos de crise. São Cristóvão: UFS, 2018a, p. 5.

xxx HUMANIDADES DIGITAIS. Disponível em $<<$ https://humanidadesdigitais.org/manifesto-dashumanidades-digitais/ $>>$. Acessado em 3 de abril de 2019.

XXXI HUMANIDADES DIGITAIS. Disponível em $<<\mathrm{https}$ ://humanidadesdigitais.org/manifesto-das-

humanidades-digitais/ $>>$. Acessado em 3 de abril de 2019.

XXXII PORTO, Cristiane de M. e MORAES, Danilo de A. Divulgação científica independente na internet como fomentadora de uma cultura científica no Brasil estudo inicial em alguns blogs que tratam de ciência. In: PORTO, C. M. (org.). Difusão e cultura científica: alguns recortes [online]. Salvador: EDUFBA, 2009, p. 110.

XXXIII Para Kenzki, tecnologia é um "conjunto de conhecimentos e princípios científicos que se aplicam ao planejamento, à construção e à utilização de um equipamento em um determinado tipo de atividade". KENSKI, Vani Moreira. Tecnologias e ensino presencial e a distância. 5. ed. Campinas: 2008.
\end{abstract}

\section{BIBLIOGRAFIA}

AFONSO, José António. Protestantismo e Educação. História de um projecto pedagógico alternativo em Portugal na transição do séc. XIX. Braga: Univ. do Minho/Instituto de Educação e Psicologia, 2009.

ALMEIDA, Mirianne Santos de. Livros e leitores: saberes e práticas educacionais e religiosas na Coleção Folhetos Evangélicos (1860-1938). Dissertação de Mestrado em Educação. Aracaju: Universidade Tiradentes, 2013.

ALVES, Josué dos S.; NASCIMENTO, Ester F. V. C. do. Construção de uma base de dados da História da Educação Protestante. Anais Eletrônicos do III Seminário Debates do Tempo Presente: Desafios para as humanidades em tempos de crise. São Cristóvão: UFS, 2018a, p. $1-10$.

AMERICAN BIBLE SOCIETY. The Manual of the American Bible Society. From the One Hundred and Tenth Annual Report of the American Bible Society. New York: American Bible Society Press, 1926.

ASSMANN, H. Reencantar a educação: rumo à sociedade aprendente. Petrópolis: Vozes, 1998.

BASTIAN, Jean-Pierre (Comp.). Protestantes, liberales y francmasones. Sociedades de ideas y modernidad en América Latina, siglo XIX. México: Fondo de Cultura Económica/CEHILA, 1993.

BRITISH AND FOREIGN BIBLE SOCIETY'S LIBRARY. Archives Indexes/BSAX (18041897). Londres: Cambridge University Library, 1956.

CHARTHIER, Roger. A aventura do livro: do leitor ao navegador. Tradução Reginaldo de Moraes. São Paulo: Editora UNESP/Imprensa oficial do Estado, 1999.

CHARTHIER, Roger. A ordem dos livros: leitores, autores e bibliotecas na Europa entre os séculos XIV e XVIII. Brasília: Editora Universidade de Brasília, 1998.

CHARTHIER, Roger. A História Cultural: entre práticas e representações. Tradução Maria Manuela Galhardo. Rio de Janeiro: Bertrand Brasil, 1990.

ELIAS, Norbert. O processo civilizador. Formação do Estado e civilização. $2^{\mathrm{a}} \mathrm{ed}$. V. I. Rio de Janeiro: Jorge Zahar Editor, 1994. 


\section{HISTÓRIA DA EDUCAÇÃO, HUMANIDADES DIGITAIS E DIVULGAÇÃO CIENTÍFICA: A BIBLIOTECA DIGITAL DE HISTÓRIA DA EDUCAÇÃO}

ESTER FRAGA VILAS-BÔAS CARVALHO DO NASCIMENTO E JOSUÉ DOS SANTOS ALVES

FARIA FILHO, Luciano Mendes. (Org.). Arquivos, fontes e novas tecnologias: questões para a história da educação. Campinas: Autores Associados/ Bragança Paulista: Universidade São Francisco, 2000.

GINZBURG, Carlo. O fio e o rastro. São Paulo: Companhia das Letras, 2007.

GONDRA, José G. A leveza dos bits. In: FARIA FILHO, Luciano Mendes. Arquivos, fontes e novas tecnologias: questões para a História da Educação. Campinas: Editores Associados, 2000, p. 3-17.

GOOGLE FOR EDUCATION. Disponível em <<https://edu.google.com/ >>. Acessado em 3 de abril de 2019.

HALLEWEL, Laurence. O livro no Brasil. São Paulo, T. A. Queiroz/Editora da Universidade de São Paulo, 1985.

HUMANIDADES DIGITAIS. Disponível em $<<$ https://humanidadesdigitais.org/manifestodas-humanidades-digitais/ $>>$. Acessado em 3 de abril de 2019.

LOPES, Eliane M. T. GALVÃO, Ana Maria de O. Território plural: a pesquisa em hitória da educação. São Paulo: Ática, 2010.

NASCIMENTO, Ester Fraga Vilas-Bôas Carvalho do. Brasil, Portugal e Inglaterra: circulação de impressos protestantes no Norte do Brasil. Anais Eletrônicos do III Congresso Nordestino de Ciências da Religião. Recife: UNICAP, 2016, p. 1-13.

NASCIMENTO, Ester Fraga Vilas-Bôas Carvalho do. Associações voluntárias, missões protestantes e a história da Educação. In: Anais Eletrônicos da 32 ${ }^{a}$ ANPEd "Sociedade, cultura e educação: novas regulações?" Caxambu: ANPEd, 2009, p. 1-13.

NASCIMENTO, Ester Fraga Vilas-Bôas Carvalho do. Educar, curar, salvar. Uma ilha de civilização no Brasil tropical. Maceió: UFAL; Aracaju: Unit, 2007.

NASCIMENTO, Jorge Carvalho do. Nota prévia sobre a palavra impressa no Brasil do século XIX: a biblioteca do povo e das escolas. Revista Horizontes. Bragança Paulista: USF, 2001, p. $11-28$.

PORTO, Cristiane de M. e MORAES, Danilo de A. Divulgação científica independente na internet como fomentadora de uma cultura científica no Brasil estudo inicial em alguns blogs que tratam de ciência. In: PORTO, C. M. (org.). Difusão e cultura cientifica: alguns recortes [online]. Salvador: EDUFBA, 2009, p. 93-112.

REILY, Ducan Alexander. História documental do protestantismo no Brasil. São Paulo: ASTE, 1984.

RIBEIRO, Domingos. 1937. Origens do evangelismo brasileiro. Rio de Janeiro: Apollo. ROCHA, Fábio Gomes. Mineração de dados edu cacionais (Educational Data Mining edm): construindo conhecimento acerca da história da educação por meio dos impressos protestantes. Aracaju: Unit, 2017 (Projeto de Pesquisa de Doutorado em Educação). 